\title{
Neuromagnetic source localization of auditory evoked fields and intracerebral evoked potentials: a comparison of data in the same patients
}

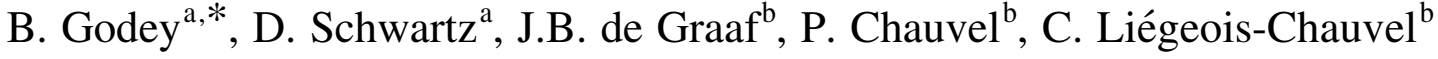 \\ ${ }^{a}$ Laboratoire IDM, UPRES-EA 3192, Faculté de Médecine, Université de Rennes I, CS 34317, Avenue du Pr. Léon Bernard, 35043 Rennes Cedex, France \\ ${ }^{\mathrm{b}}$ INSERM E 9926, Laboratoire de Neurophysiologie et Neuropsychologie, Université de la Méditerranée, Marseille, France
}

Accepted 6 July 2001

\begin{abstract}
Objective: To compare the localizations of different neural sources (a) obtained from intracerebral evoked responses and (b) calculated from surface auditory evoked field responses recorded in the same subjects. Our aim was to evaluate the resolving power of a source localization method currently used in our laboratory, which is based on a recent spatio-temporal algorithm used in magneto-encephalography (MEG).

Methods: Auditory evoked responses were studied in 4 patients with medically intractable epilepsy. These responses were recorded from depth electrodes implanted in the auditory cortex for pre-surgical evaluation (stereo-electro-encephalography (SEEG)), as well as from surface captors (for MEG) placed on the scalp after removal of the depth electrodes. Auditory stimuli were clicks and short tone bursts with different frequencies.

Results: All middle-latency components (from 13 to $70 \mathrm{~ms}$ post-stimulus onset) were recorded and localized (via SEEG) along Heschl's gyrus (HG). MEG reliably localized Pam and P1m in the same area of HG that intracerebral recordings localized them in. No significant delay between SEEG and MEG latencies was observed. Both methods suggest that N1 is generated from different sources in the intermediate and lateral parts of the HG and in the planum temporale (PT). The source of P2 (PT and/or Area 22) remains unclear and was in one case, localized in different regions according to the method used. This latter component may therefore also be generated by different sources.

Conclusions: The results suggest that both techniques are useful and may be used together in a complementary fashion. Intracerebral recordings allow the researcher to validate and interpret surface recordings. (C) 2001 Elsevier Science Ireland Ltd. All rights reserved.
\end{abstract}

Keywords: Auditory evoked responses; Depth recordings; Magneto-encephalography; Source localization

\section{Introduction}

Different components of an auditory evoked potential (AEP) can be isolated and described as a function of latency, scalp topography, and the perceptual/cognitive process to which they are associated. Each component underlies a different aspect of auditory processing, beginning in the cochlea and terminating in the auditory cortex. The earliest components $(<20 \mathrm{~ms})$, corresponding to activity in the thalamo-cortical volley, are not reliably identifiable from the scalp. Several middle-latency potentials, however, can be identified from the scalp: $\mathrm{Na}$ (or Nam in the MEG literature) at $19 \mathrm{~ms}, P a$ (or $P a m$ ) at $30 \mathrm{~ms}, N b$ (or $N b m$ ) at $40 \mathrm{~ms}$, and $\mathrm{Pb}$ or $\mathrm{Pl}(\mathrm{Pbm}$ or $\mathrm{Plm})$ at $50 \mathrm{~ms}$. Neuromagnetic data show that, while the Pam component is consistently observed in normal subjects, the other 3 are less reliable,

\footnotetext{
* Corresponding author. Tel.: +33-2-99-33-68-63; fax: +33-2-99-33-6864.

E-mail address: benoit.godey@wanadoo.fr (B. Godey).
}

occurring more or less frequently according to the study (Pelizzone et al., 1987; Reite et al., 1988; Scherg et al., 1989; Pantev et al., 1990, 1993; Mäkelä et al., 1994). Pam's source has been localized in a region more anterior and more medial to that generating N1m (a large, robust late auditory evoked response peaking at $100 \mathrm{~ms}$ ), suggesting that these components are generated in different regions of the auditory cortex. While $P l$, however, is thought to be generated in the primary auditory cortex (Huotilainen et al., 1998; Reite et al., 1988), neuromagnetic techniques fail to provide much data on the underlying neural sources of this and other middle-latency components because of the small amplitude that these components often have. Their sources may be localized more reliably from intracerebral recordings using depth electrodes implanted in the auditory cortex for the pre-surgical evaluation of medically intractable epilepsy.

In order to accurately localize and delineate the epileptic zone in the epileptic subject, pre-surgical evaluation (stereoelectro-encephalography (SEEG)) requires the stereotaxic 
implantation of multiple depth electrodes (Bancaud et al., 1965). Because the size and location of each cortectomy is different for each patient, it is important to have high spatiotemporal resolution of ictal and inter-ictal electrical activity. The superior temporal gyrus (STG) is a key structure in lateral and mesial-lateral temporal lobe epilepsy and is frequently evaluated intracerebrally (Bancaud and Talairach, 1992). Situated in the STG, the auditory cortex consists of several different anatomical structures. It includes the transverse gyri of Hschl (the dorso-postero-medial part of which corresponds to the primary auditory cortex; the lateral part of which corresponds to the secondary areas (LiégeoisChauvel et al., 1991)). The secondary areas continue caudally onto the planum temporale (PT) and extend ventrally above and slightly below the superior temporal sulcus.

Previous data suggest the existence of at least 7 middlelatency generators underlying their respective components at $13,16,30,50,60,75$, and $100 \mathrm{~ms}$. Their sources are localized in different regions along the Heschl's gyrus (HG). N/P 16 and 30 originate from the most medial part of the primary cortex (i.e. the dorso-postero-medial part of the HG); N/P $50(P l)$ is generated in the lateral part of the primary cortex; N/P 60 and 75 originate from the intermediate or lateral part of the HG (secondary cortex); and the N100 has at least two generators - one in the lateral part of HG and one in the PT (Liégeois-Chauvel et al., 1991, 1994). With respect to the generator of this latter component, much of the previous data has been discordant with some authors suggesting its localization in the primary auditory cortex (Pantev et al., 1994, Huotilainen et al., 1998).

Intracerebral recordings provide direct and accurate information on the localization of a component's generator. Scalp recordings, on the other hand, provide at best an estimate of a generator's localization, which must be calculated and which cannot be measured directly. Localizing these sources accurately requires the modeling of intracerebral sources and of the head, and the choice of the model affects spatial and temporal accuracy. While this presents a challenge for electroencephalography (EEG), magnetoencephalography (MEG) is a non-invasive technique, which offers better spatial resolution owing to highly sensitive captors and to the fact that it is less subject to interference from the skull than is EEG (Wikswo et al., 1993; Gevins, 1996). Recently, we had the opportunity to record and study neuromagnetic scalp and intracerebral AEPs in the same patients, making a comparison between magnetic source localization and source localization using depth electrodes possible.

The aim of the present study was to compare intracerebral and scalp auditory evoked responses and their respective source localizations. Such an endeavor would help us better appreciate the resolving power of the spatio-temporal algorithm currently used for MEG in our laboratory and could ultimately help assess the localization capacity and utility of non-invasive techniques in clinical settings.

\section{Methods}

\subsection{Subjects}

Recordings were carried out in 4 right-handed adult patients ( 3 males; one female), aged 21-43 years, with medically intractable partial seizures. In no patient was the epileptogenic foyer localized in the STG. During each recording session, subjects were laid comfortably in a bed and were instructed to remain attentive. In 3 patients, the right hemisphere was explored; in one patient, the left hemisphere was explored.

All subjects gave informed consent for all of the examinations and investigations carried out.

\subsection{Auditory stimulation}

Sound stimuli were short tone bursts (with a total duration of $50 \mathrm{~ms}$ and rise and decay times of $3 \mathrm{~ms}$ ) presented at 70 dB. Stimuli were presented at 3 different frequencies (500 $\mathrm{Hz}, 1$, and $2 \mathrm{kHz}$ ) and were presented in the ear controlateral to the recording side at a rate of one per second. In one patient (Case 1), a click (with a total duration of $1 \mathrm{~ms}$ ) was also presented. The same stimuli were used in each of the two (SEEG and MEG) recording sessions.

\subsection{Anatomical description of depth electrode sites}

Multilead electrodes $(0.8 \mathrm{~mm}$ diameter, 5-15 contacts, 2 $\mathrm{mm}$ length, $1.5 \mathrm{~mm}$ apart) were introduced orthogonally through a double grid system fastened to a Talairach stereotaxic frame. The anatomical localization of each lead was based on a stereotaxic method described elsewhere (Talairach and Tournoux, 1988; Liégeois-Chauvel et al., 1991). Because of the oblique orientation of $\mathrm{HG}$, a single electrode can run through (and thus be used to study) different auditory areas (medial and/or lateral parts of HG, and/or PT, and/or Area 22).

- In Case 1, an electrode with 9 leads was implanted: 3 were medial leads in the medial part of left HG; 5 were lateral leads in left PT; one was extra-cortical.

- In Case 2, an electrode with 5 leads was implanted: 4 in the lateral part of the right $\mathrm{HG}$ and one extra-cortical.

- In Case 3, electrode P had 15 leads: 7 in the right PT and 8 in the white matter between the cortex and the ventricle.

- In Case 4, an electrode with 5 leads was implanted in Area 22 (anterior to the HG) in the right hemisphere.

The anatomical structures studied in each case were identified by visualizing the electrode tracks with stereotaxic magnetic resonance imaging (MRI), once the electrodes were removed (Fig. 1). 


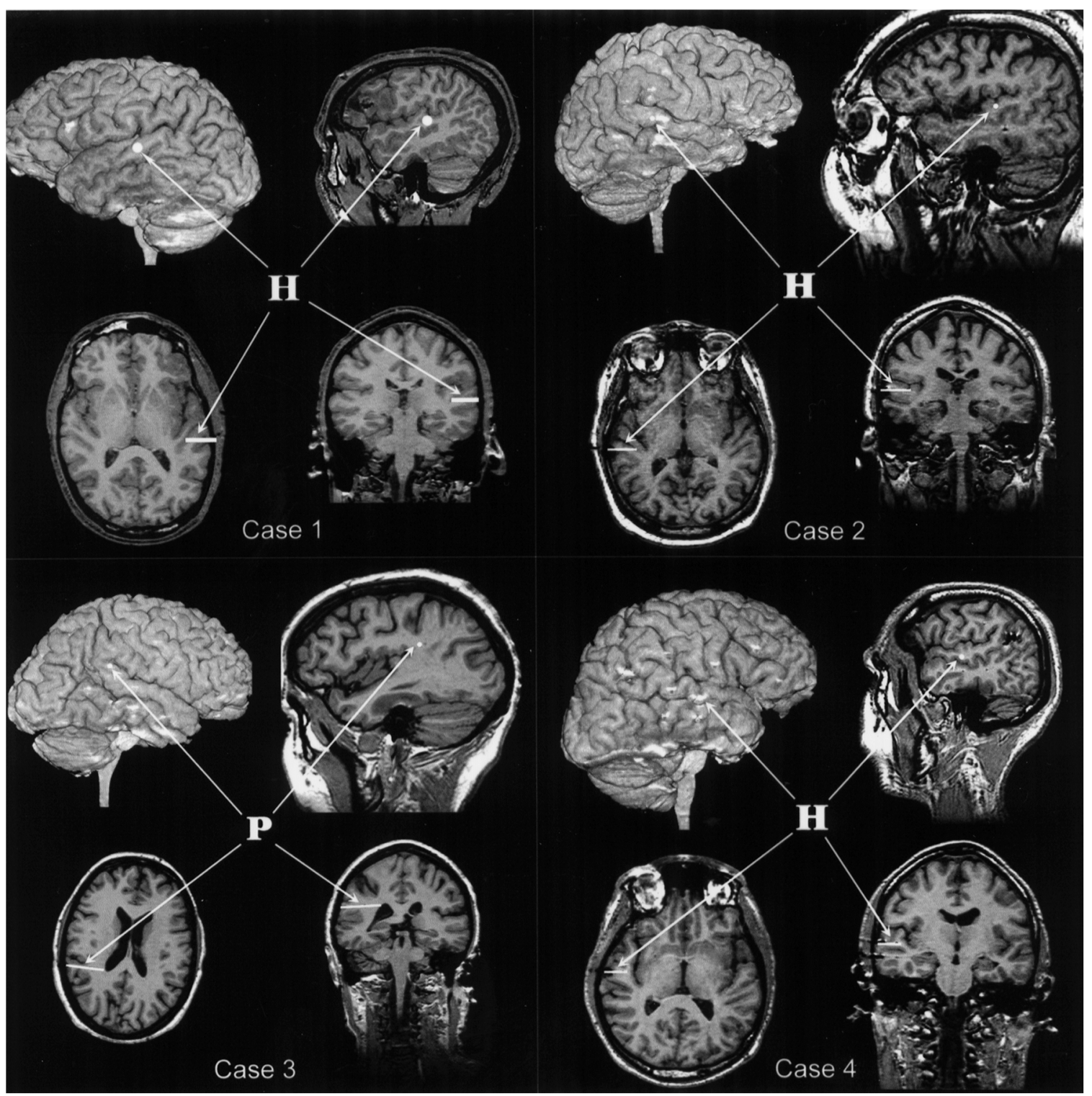

Fig. 1. Anatomical localizations of depth electrodes, the traces of which have been underlined on MRI performed after the removal of electrodes. MRI surface (top left) and sagittal, axial, and coronal slices (top right, bottom left, and bottom right, respectively) in 4 patients (see comments in the text).

\subsection{Data acquisition}

\subsubsection{SEEG recording}

Intracerebral AEPs were recorded from all contacts on all depth electrodes (referenced to an extra-dural lead) and were sampled, amplified, and filtered ( $1 \mathrm{~Hz}-1.5 \mathrm{kHz})$ before storage. The duration of each epoch was $400 \mathrm{~ms}$ with a prestimulus time of $40 \mathrm{~ms}$. One hundred trials were averaged for each sound.

For each component, the leads between which an inversion of polarity was observed (or, in certain cases, the lead at which amplitude was markedly greater than elsewhere) were identified. These parameters indicate that the electrode has passed through the region generating a component (Schwartz, 1998).

\subsection{2. $M E G$ recording}

MEG recordings were carried out after removal of the depth electrodes and before cortical resection. Neuromagnetic measurements were taken with a 37-channel biomagnetometer (Magnes ${ }^{\mathrm{TM}}$, Biomagnetic Technologies), in a magnetically and electromagnetically shielded room. The detector coils of the biomagnetometer were arranged in a circular concave array with a diameter of $144 \mathrm{~mm}$ and a spherical radius of $122 \mathrm{~mm}$. The axis of the coils was perpendicular to the sphere. The diameter of each coil was $20 \mathrm{~mm}$ and the distance between the center of two adjacent coils was $22 \mathrm{~mm}$. The total sensitivity was between 5 and $7 \mathrm{fT} / \sqrt{\mathrm{Hz}}$. Captors were placed over the entrance points of each depth electrode, as near as possible to the subject's head. A sensor position indicator system (Polhemus Fast Track) determined 
the spatial locations of the captors relative to the head (with a precision of $0.8 \pm 0.07 \mathrm{~mm}$ ). The duration of each epoch was $500 \mathrm{~ms}$ with a pre-stimulus time of $100 \mathrm{~ms}$. Responses from each channel were filtered on-line between 1 and $400 \mathrm{~Hz}$, and sampled at $1041 \mathrm{~Hz}$. Five hundred trials were averaged for each stimulus and an automatic artifact rejection at a fixed amplitude level was employed during averaging. The bandpass filter was set at $1-120 \mathrm{~Hz}$.

The origin of the head frame coordinate system was the midpoint between the left and right pre-auricular points. The $x$-axis extended from the origin to the nasion and the $z$-axis extended from the origin to the top of the head such that it was perpendicular to the plane formed by the nasion and the pre-auricular points. The $y$-axis extended from the origin to the left side of the head such that it was perpendicular to the $x$ - and $z$-axes.

A spatio-temporal (SPTF) method (described elsewhere, Schwartz et al., 1999) was used for the localization of sources. The SPTF algorithm applies principal component analysis (PCA) over a short, moving time window (generally $5 \mathrm{~ms}$ ) to separate simultaneous asynchronous dipolar sources. A homogeneous sphere model was used to define the head. The SPTF has been shown previously (Schwartz et al., 1996, 1999) to yield stable localizations and is relatively uninfluenced by noise. The analysis window was shifted along the signal in steps of $1 \mathrm{~ms}$. Only those dipoles with a correlation of greater than $98 \%$ between the estimated and calculated sources were taken into account. After MEG with MRI automatic registration, results were transposed onto MRIs obtained from each subject. This procedure was carried out by matching MRI segmented scalp surface with the digitized head using a three-dimensional (3D) tracker in the same reference system as was used for the positions of the MEG captors, with an estimated error of 2-3 mm (Schwartz et al., 1996).

\section{Results}

Fig. 2 (top) shows AEPs recorded in Case 1 from 9 consecutive leads along electrode $\mathrm{H}^{\prime}$ in the medial part of left $\mathrm{HG}$ (3 leads $\left(\mathrm{H}^{\prime} 1-3\right)$ ) and PT (5 leads $\left(\mathrm{H}^{\prime} 4-8\right)$ ) in response to the click stimuli. Lead $\mathrm{H}^{\prime} 1$ recorded short-latency evoked responses (N15/P20/N30) characteristic of responses from the primary auditory cortex, followed by middle-latency components (P45/N60) and a slow-wave peaking around $90 \mathrm{~ms}$. The amplitudes of the early components were smaller on leads $\mathrm{H}^{\prime} 2$ and $\mathrm{H}^{\prime} 3$ and disappeared entirely on lead $\mathrm{H}^{\prime} 4$ (i.e. in PT). The AEPs recorded in the $\mathrm{PT}$ reflected a large N35/P55/N80/P115 complex. A double polarity inversion of the $50 \mathrm{~ms}$ component was observed: the first between leads $\mathrm{H}^{\prime} 1$ and $\mathrm{H}^{\prime} 3$ (indicating the presence of a generator in the cortical region between these leads), and the second between the third and fourth leads, where the electrode ran between HG and PT. A shift in latency and less focal responses were seen along the leads implanted in the PT
$\left(\mathrm{H}^{\prime} 4-\mathrm{H}^{\prime} 8\right)$. The generator of the $80 \mathrm{~ms}$ component was also identified by the polarity inversion observed between HG and PT.

These results were compared with the MEG data obtained from the same patient (Case 1). Fig. 2 (bottom) shows a superposition of the 37 responses to click stimuli. No identifiable components before $30 \mathrm{~ms}$ were observed. Polarity inversions of the middle-latency components $(30,57$, and 76 $\mathrm{ms}$ ), as well as a slow-wave peaking at $110 \mathrm{~ms}$ can be observed.

Fig. 3 shows source localizations for these middle-latency components on the MRI slices of the position of the $30 \mathrm{~ms}$ component, compared to the position of the electrode. The projection of the $57 \mathrm{~ms}$ component on the 3 slices and of the $76 \mathrm{~ms}$ component on the axial slice are represented by dotted marks because they were not localized on these slices.

Generators of the $30 \mathrm{~ms}$ Pa component were found along the dorso-postero-medial part of the $\mathrm{HG}$, close to the medial leads of electrode $\mathrm{H}^{\prime}$. The source of the $57 \mathrm{~ms}$ component (P1) was localized between the sources of the 30 and $76 \mathrm{~ms}$ components. The $76 \mathrm{~ms}$ component was generated between the intermediate and lateral parts of $\mathrm{HG}$, close to the lateral leads of electrode $\mathrm{H}^{\prime}$, while the source of $\mathrm{N} 1$ (110 ms) was localized in the lateral part of the $\mathrm{HG}$, posterior and lateral to the generator of the $76 \mathrm{~ms}$ component (not shown) (Fig. 3).

Fig. 4 shows intracerebral AEPs and MEG recordings for Cases 2- 4, in response to tone bursts of $1 \mathrm{kHz}$. In the upper half of the figure are recordings for the right $\mathrm{HG}$ (Case 2), right PT (Case 3), and right Area 22 (Case 4) anterior to the HG. The AEPs changed in their morphology and amplitude as a function of recording site. In HG (Case 2 ), evoked responses changed along the electrode. The polarity inversion between leads $\mathrm{H} 1$ and $\mathrm{H} 2$ and leads $\mathrm{H} 2$ and $\mathrm{H} 3$ for the $37 \mathrm{~ms}$ component suggests that the source of this component was located in a cortical region between these leads.

Responses recorded in Case 3 from the 7 lateral-most leads in PT (the 8 medial leads located in the white matter are not shown) are displayed in Fig. 4. P1 (45 ms) was recorded from leads $\mathrm{P} 11$ to $\mathrm{P} 14$ but no polarity inversion indicating the presence of a generator in the regions investigated was observed. Responses recorded from PT (Case 3) were of greater amplitude (N70-80/P120) and of different polarity than those recorded from the HG. In Area 22 (Case 4), volume-conducted responses were recorded from a wider region of Area 22. No reversal of polarity or amplitude gradient along the different leads was observed. Latencies correspond to those recorded from the HG.

Averaged MEG responses are shown in Fig. 4 (bottom) for the same 3 patients with the same stimuli (tone burst, 1 $\mathrm{kHz}$ ). Captor positions were different for each patient because captors were fixed near electrode entrance points. Two components were consistently identified from MEG recordings: Pam (35, 34, and $30 \mathrm{~ms})$ and $\mathrm{N} 1$ (81, 80, and 

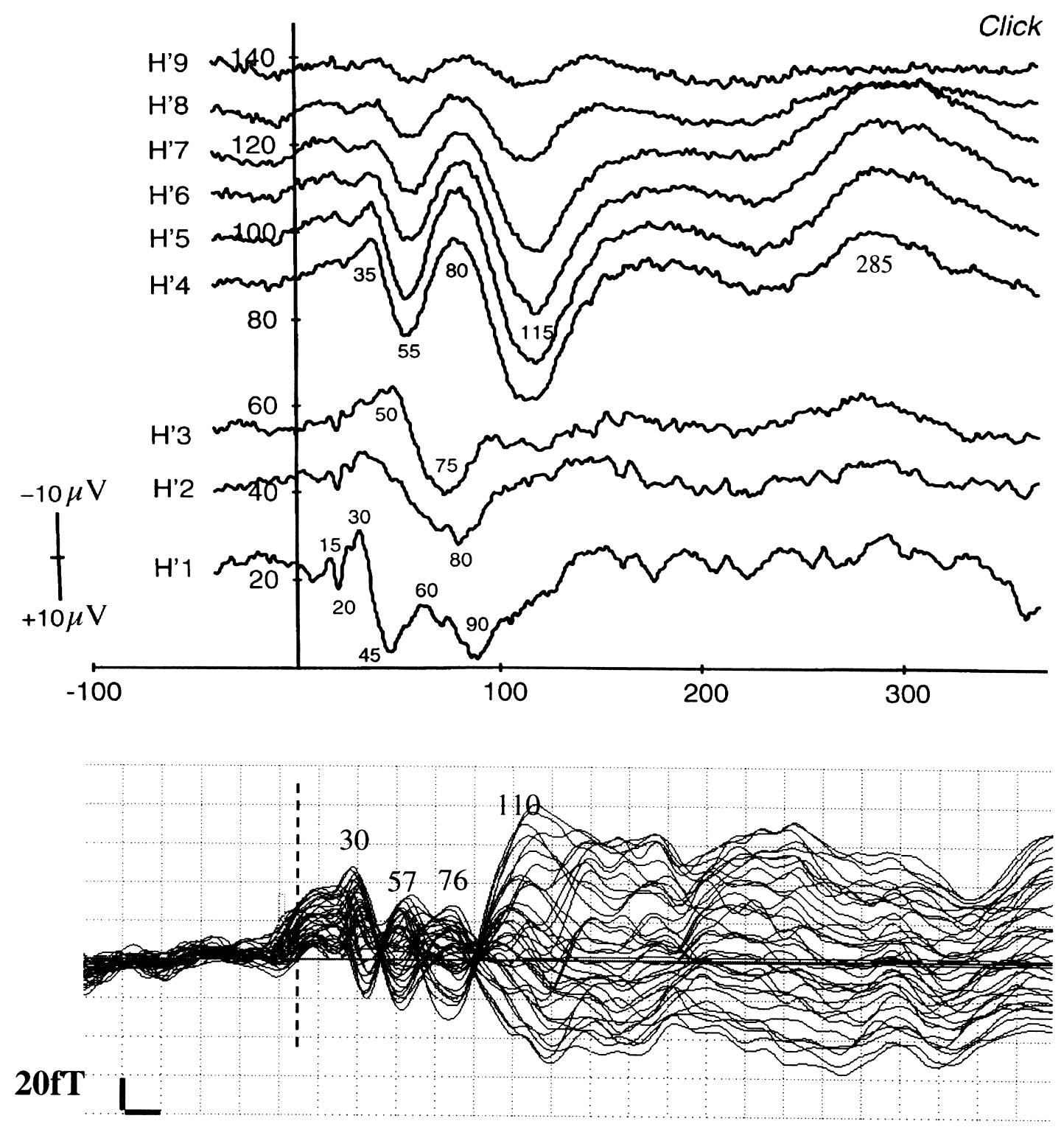

$20 \mathrm{~ms}$

Fig. 2. Comparison of auditory evoked responses recorded from a depth electrode (top) and using MEG (bottom) in Case 1. Top, auditory response evoked by a click stimulation recorded on each lead of electrode $\mathrm{H}^{\prime}$ exploring from the left auditory cortex. The most medial lead is the first one and the most lateral one is the ninth. Note the difference in morphology and amplitude of responses recorded between (i) lead 1 and leads 2-3, and (ii) between these latter ones and leads 4-8, showing that the electrode passes through different auditory areas. Negative polarity is up. Bottom, superposition of the 37 waveforms recorded by MEG over the temporal lobe from the same subject and the latencies of peaks $30,57,76$, and $110 \mathrm{~ms}$.

$84 \mathrm{~ms})$; N1 was made up of a main N1a component (70-84 $\mathrm{ms})$, followed $10-40 \mathrm{~ms}$ later by a smaller component with a polarity reversal. This second component is most notable in Case 4. This component had a latency of $120 \mathrm{~ms}$ (MEG) and $110 \mathrm{~ms}$ (SEEG) and could correspond to N1c. In Case 2, it had a latency of $104 \mathrm{~ms}$ (MEG, pointed by arrow) and would correspond to N1b. No SEEG equivalent to N1b was observed.

In Cases 2 and 3 (MEG data), N1 was followed by waves peaking at 163 and $150 \mathrm{~ms}$ (N200). In Case 4, the $208 \mathrm{~ms}$ component (SEEG) was not observed from the MEG data. No components before $30 \mathrm{~ms}$ were identifiable or localizable from the MEG data.

The dipole localizations of the N1 components identified are represented in Fig. 5. Using a spatio-temporal algorithm, dipoles with the best correlation between estimated and calculated sources $(>98 \%)$ do not always correspond to the peaks. In Case $2, \mathrm{~N} 1 \mathrm{~m}(81 \mathrm{~ms})$ was localized in the intermediate part of HG (i.e. Area 42). In Cases 3 and 4, dipoles corresponding to components with latencies of 80 


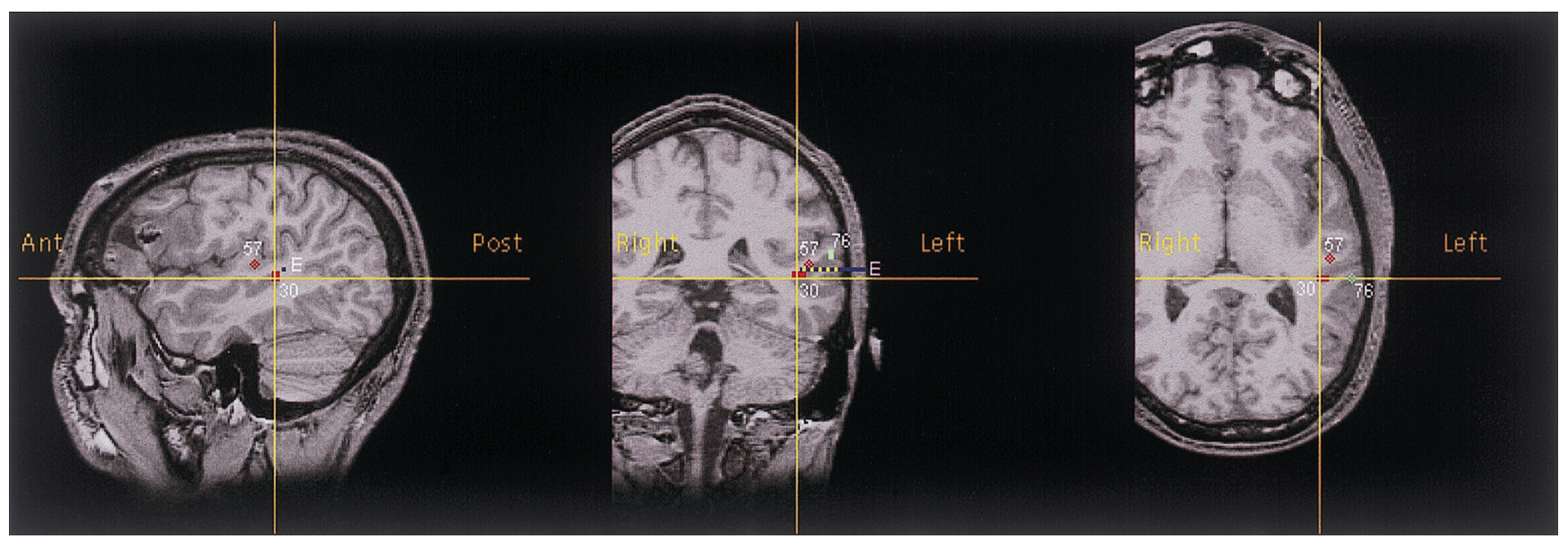

Fig. 3. Localization of 30, 57, and $76 \mathrm{~ms}$ magnetic response on the Case 1's MRI compared to the anatomical position of the depth electrode. The projection of the $57 \mathrm{~ms}$ component on the 3 slices and of the $76 \mathrm{~ms}$ component on the axial slice are dotted marked. On the sagittal view, the $76 \mathrm{~ms}$ component is not represented because the projection should be superimposed on the $30 \mathrm{~ms}$ component. On the axial view, the electrode is not represented because it is not localized on this slice.

and $84 \mathrm{~ms}$, respectively were localized more laterally, in the lateral part of the HG.

Table 1 summarizes the different components obtained using each of the two techniques with tone bursts and clicks as stimuli. $\mathrm{Nb}$ was observed with the MEG data of Case 2 only and was localized in the medial part of the HG (not represented in this table). The N60/70 component was observed in the SEEG data and is represented with N1, as previously described (Näätänen and Picton, 1987). Component latencies were similar between both techniques. Small differences in latency may be explicable by the fact that recordings were not performed at the same time. Table 1 shows that P1 was observed more often with SEEG than with MEG.

SEEG and MEG localized generators in the same regions in all cases except for the generator of $\mathrm{P} 2$ in one patient (case 3, $500 \mathrm{~Hz}$ ). The Pa generator was localized with both techniques in the medial and intermediate parts of the $\mathrm{HG}$ in the primary auditory cortex. P1 was localized in the intermediate part of the HG between the primary and secondary

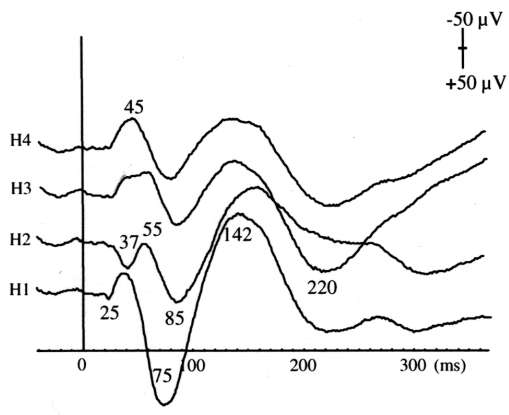

Case 2

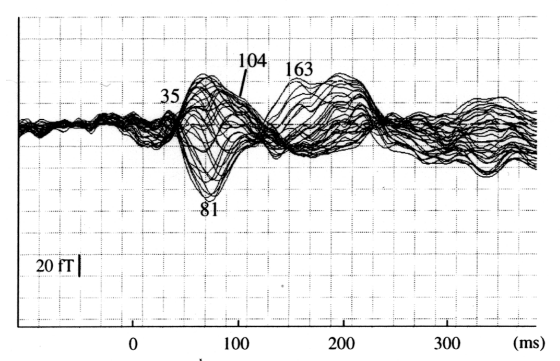

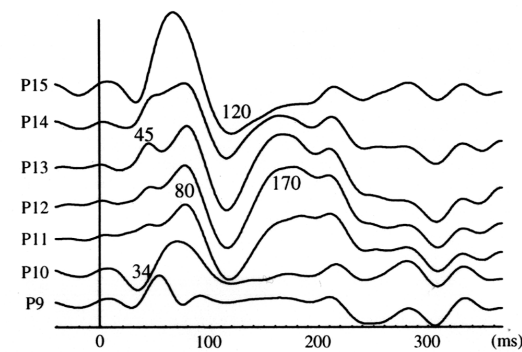

Case 3

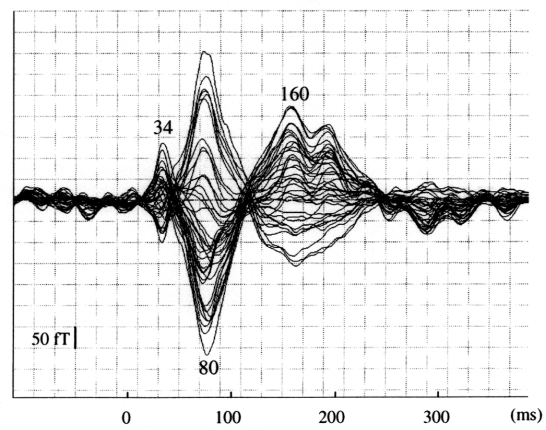

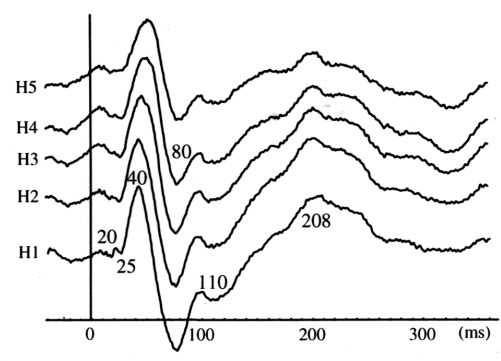

Case 4

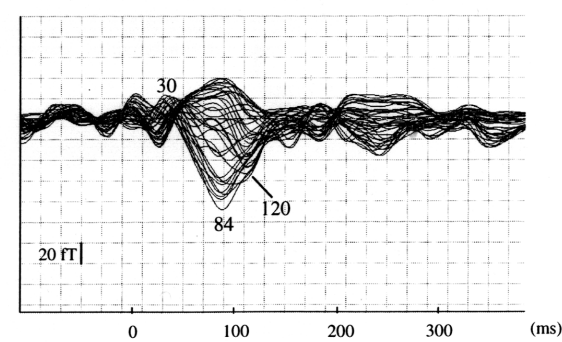

Fig. 4. Comparison of depth recordings (top) and magnetic recordings (bottom) in 3 patients. The auditory stimulus is a tone burst of $1 \mathrm{kHz}$. 
auditory cortices, and, in one case, in the lateral part of the HG. Different sub-components of N1 could be recorded. N60/70 was localized from the SEEG data in the intermediate part of the HG. N1a was most often localized in the intermediate part of the $\mathrm{HG}$, but was also localized (in Case $3(1 \mathrm{kHz})$ and Case $4(0.5-1 \mathrm{kHz}))$ in the lateral part of this structure, and in Area 22 (in Case $2(0.5 \mathrm{kHz})$ ). N1b was localized in the secondary auditory cortex - most often in the lateral part of the $\mathrm{HG}$, and also in Area 22 in the case of one patient (Case $2(2 \mathrm{kHz})$ ). N1c was also localized in the lateral part of the HG. The late P2 component was localized from the SEEG data in PT (for two patients) and in Area 22 (in one patient) in the secondary auditory cortex. It should be noted, however, that the generators of only a few components could be localized, due to the high sensitivity of electrode leads which only record activity from generators in close proximity to the electrode.

\section{Discussion}

The localization of generators from the SEEG data yielded similar results to those cited previously (Liégeois-
Chauvel et al., 1994). In Case 1 (using click stimuli), most of the middle-latency potentials (13-50 ms post-stimulus onset) previously recorded in the primary auditory cortex (Liégeois-Chauvel et al., 1991, 1994) were observed. These responses show a polarity inversion compared to EEG surface responses (Streletz et al., 1977; Özdamar and Kraus, 1983; Cacace et al., 1990) (i.e. N15 corresponds to $\mathrm{P} 0, \mathrm{P} 20$ to $\mathrm{Na}, \mathrm{N} 30$ to $\mathrm{Pa}$, and P/N50 to P1). Of these components, however, only $\mathrm{Pa}$ was observed using MEG. Early components (with the exception of $\mathrm{Pa}$ ) are more difficult to observe using MEG than using EEG. These findings are consistent with data obtained previously (Deiber et al., 1988). In fact, in none of the 4 cases studied here were components with latencies earlier than $30 \mathrm{~ms}$ observed for any of the auditory stimuli used. Pantev et al. (1995) have suggested that tone bursts with relatively long durations (i.e. $50 \mathrm{~ms}$ ) do not have a strong enough synchronization effect to reliably elicit waves earlier than the $\mathrm{Pa}$ component. In Case 1 of our study, however, no early components were recorded with click stimuli either. The generators of very early components (N13/P16 (i.e. P0, Na)) are localized at the tip of the HG (Liégeois-Chauvel et al., 1991), however, and it is likely that MEG is not a sensitive enough measure

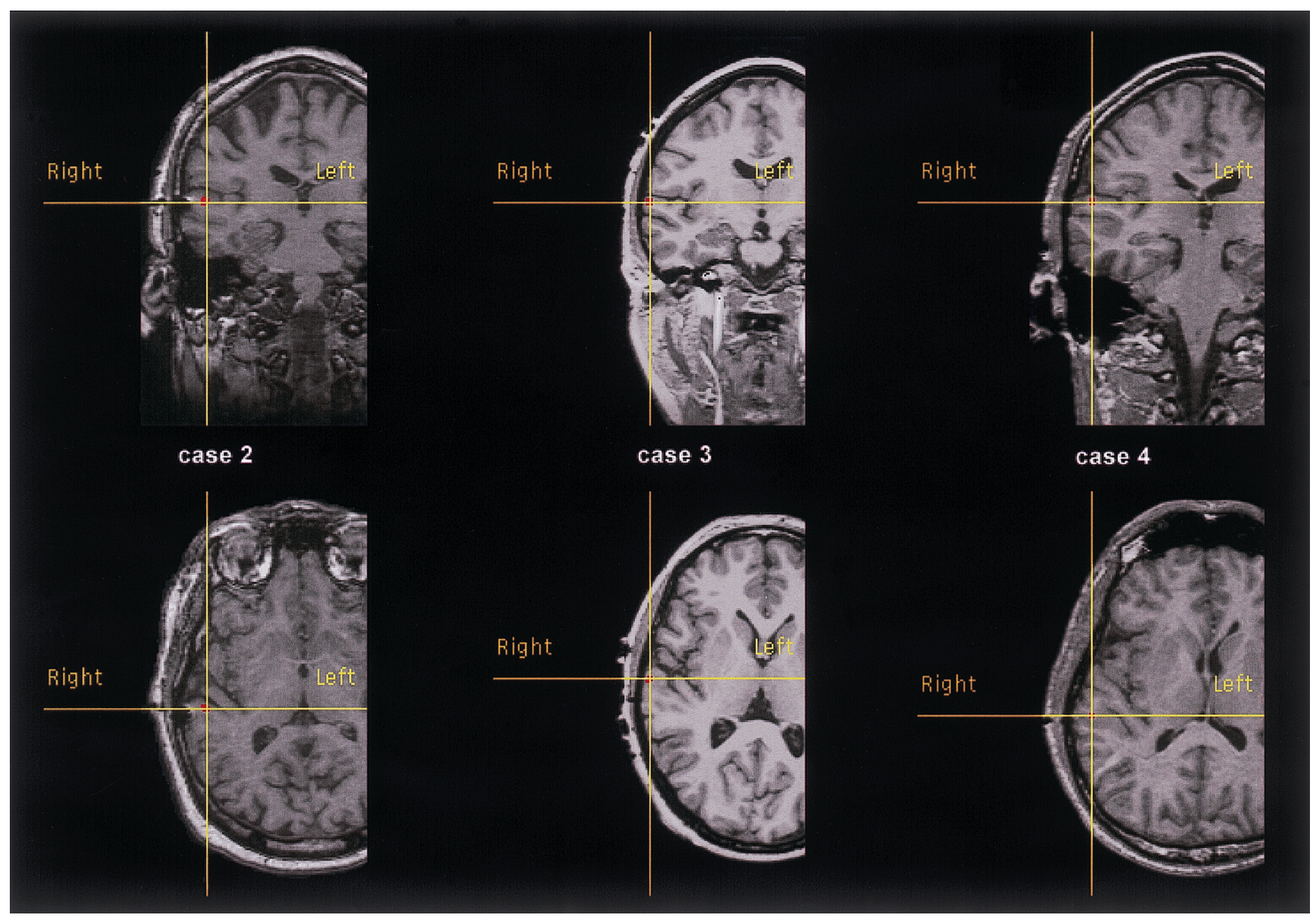

Fig. 5. Localization of N1a magnetic responses on the Case 3's MRI. The auditory stimulus is a tone burst of $1 \mathrm{kHz}$. 
Table 1

Comparison between localization and latency of cortical generators recorded by MEG and SEEG ${ }^{\mathrm{a}}$

\begin{tabular}{|c|c|c|c|c|c|c|c|c|c|c|c|c|}
\hline & $\mathrm{Pa}$ & & & $\mathrm{P} 1$ & & & N1 & & & $\mathrm{P} 2$ & & \\
\hline & $\begin{array}{l}\text { Latency } \\
\text { MEG (ms) }\end{array}$ & $\begin{array}{l}\text { Latency } \\
\text { SEEG (ms) }\end{array}$ & Area & $\begin{array}{l}\text { Latency } \\
\text { MEG (ms) }\end{array}$ & $\begin{array}{l}\text { Latency } \\
\text { SEEG (ms) }\end{array}$ & Area & $\begin{array}{l}\text { Latency } \\
\text { MEG (ms) }\end{array}$ & $\begin{array}{l}\text { Latency } \\
\text { SEEG (ms) }\end{array}$ & Area & $\begin{array}{l}\text { Latency } \\
\text { MEG (ms) }\end{array}$ & $\begin{array}{l}\text { Latency } \\
\text { SEEG }(\mathrm{ms})\end{array}$ & Area \\
\hline \multicolumn{13}{|l|}{ Case 1} \\
\hline Clicks & 30 & 30 & $H G m$ & 57 & 55 & $H G i$ & $\left\{\begin{array}{r}76(a) \\
110(c)\end{array}\right.$ & $\begin{array}{l}80 \\
115\end{array}$ & $\begin{array}{l}\boldsymbol{H} \boldsymbol{G i} \\
\mathrm{HGl}\end{array}$ & - & 285 & \\
\hline $500 \mathrm{~Hz}$ & 28 & 32 & $H G m$ & - & - & & $\left\{\begin{array}{l}70(a) \\
92(b)\end{array}\right.$ & $\begin{array}{l}65(\mathrm{~N} 60-70) \\
102\end{array}$ & $\begin{array}{l}\boldsymbol{H G i} \\
\mathrm{HGl}\end{array}$ & 170 & 175 & $P T$ \\
\hline $\begin{array}{l}1000 \mathrm{~Hz} \\
2000 \mathrm{~Hz}\end{array}$ & - & $\begin{array}{l}35 \\
33\end{array}$ & $H G m$ & - & $\begin{array}{l}48 \\
57\end{array}$ & $H G i$ & $\begin{array}{l}95(\mathrm{~b}) \\
97(\mathrm{~b})\end{array}$ & $\begin{array}{l}99 \\
106\end{array}$ & $\begin{array}{l}\mathrm{HGl} \\
\mathrm{HGl}\end{array}$ & - & $\begin{array}{l}242 \\
241\end{array}$ & $P T$ \\
\hline \multicolumn{13}{|l|}{ Case 2} \\
\hline $500 \mathrm{~Hz}$ & 39 & 39 & $H G i$ & - & - & & $\left\{\begin{array}{l}85(a) \\
\text {. }\end{array}\right.$ & $\begin{array}{l}64(\mathrm{~N} 60-70) \\
99\end{array}$ & a22 & 145 & 158 & PT \\
\hline $1000 \mathrm{~Hz}$ & 35 & 37 & $H G i$ & - & 55 & & $\left\{\begin{array}{r}81(a) \\
104(b)\end{array}\right.$ & $\begin{array}{l}85 \\
-\end{array}$ & $\begin{array}{l}\text { HGi } \\
\mathrm{HGl}\end{array}$ & 163 & 142 & PT \\
\hline $2000 \mathrm{~Hz}$ & - & - & & - & 54 & & $\{96(b)$ & $\begin{array}{l}\text { 65(N60-70) } \\
-\end{array}$ & $\begin{array}{l}H G i \\
\text { a22 }\end{array}$ & - & 146 & \\
\hline Case 3 & & & & & & & & & & & & \\
\hline $500 \mathrm{~Hz}$ & - & 30 & & 51 & 47 & HGl & $106(c)$ & 124 & HGl & 142 & 130 & $P T / \mathrm{a} 22$ \\
\hline $1000 \mathrm{~Hz}$ & 34 & 34 & $\mathrm{HGi}$ & - & 45 & & 80 (a) & 80 & HGl & 160 & 170 & a22 \\
\hline $2000 \mathrm{~Hz}$ & - & 32 & $\mathrm{HGi}$ & - & 42 & & $96(b)$ & - & HGl & 153 & 140 & a22 \\
\hline Case 4 & & & & & & & & & & & & \\
\hline $500 \mathrm{~Hz}$ & 34 & - & $\mathrm{HGi}$ & 48 & 51 & & 87(a) & 97 & HGl & - & - & \\
\hline $1000 \mathrm{~Hz}$ & 30 & 40 & $\mathrm{HGm}$ & - & - & $\mathrm{HGi}$ & $\left\{\begin{array}{r}84(a) \\
120(c)\end{array}\right.$ & $\begin{array}{l}80 \\
110\end{array}$ & $\begin{array}{l}\text { HGl } \\
\text { HGl }\end{array}$ & - & 208 & \\
\hline $2000 \mathrm{~Hz}$ & 36 & - & $\mathrm{HGm}$ & 53 & 52 & $\mathrm{HGi}$ & $\left\{\begin{array}{l}74(a) \\
97(b)\end{array}\right.$ & $\begin{array}{l}- \\
-\end{array}$ & $\begin{array}{l}\text { HGi } \\
\text { HGl }\end{array}$ & 170 & - & a22 \\
\hline
\end{tabular}

${ }^{\text {a }} \mathrm{HGm}$, medial part of Heschl gyrus; HGi, intermediate part of Heschl gyrus; HGl, lateral part of Heschl gyrus; PT, planum temporale; a22, area 22. (a), N1a; (b), N1b; (c), N1c. Localizations in bold italics are localized by SEEG and MEG. Generators localized by only SEEG are italicized. Generators localized by only MEG are neither bold nor bold italics.

to detect such deep sources. To our knowledge, the two studies to observe an early component (N19) using MEG with click stimuli are those of Scherg et al. (1989) and Yoshiura et al. (1996), who obtained their data using averages of 1600 and 4000 epochs, respectively.

While the Nbm component was observed using MEG (in Case 2), it was not consistently discernible. This observation has been reported previously (Pantev et al., 1993, 1995; Mäkelä et al., 1994). In one patient, source localization from the MEG data and anatomical localization of generators from the SEEG data converged for this component, suggesting a localization in the medial part of the HG in a region overlapping the generator of the $30 \mathrm{~ms}$ component.

$\mathrm{P} 1 \mathrm{~m}$ was observed from the MEG data in 3 patients, but in only one stimulation in each patient, and was localized in the lateral part of the primary cortex (intermediate part of HG), corresponding to the localization found intracerebrally in Case 1. Several MEG studies have reported that P1m is not consistently observed in all conditions. Mäkelä et al. (1994) studied the distribution of middle-latency evoked fields using a whole head system. These authors showed that $\mathrm{P} 1 \mathrm{~m}$ was recorded more often from the hemisphere ipsilateral to stimulation (10 out of 14 hemispheres), than from the controlateral hemisphere (4 out of 14 hemispheres). They suggested that this could be due to the P1m component being 'cancelled out' by the N1m component, which has an inverse polarity. Indeed, N1m has a greater amplitude and an earlier latency when stimuli are presented controlaterally and generates a magnetic field largely overlapping that of $\mathrm{P} 1 \mathrm{~m}$, which, as a result, is difficult to isolate. Nevertheless, some authors have recorded P1m from both hemispheres (Farrell et al., 1980; Pelizonne et al., 1987; Reite et al., 1988), sometimes with an earlier latency in the right than in the left hemisphere (Huotilainen et al., 1998). The presence of this wave seems to be highly dependent on the frequency stimulus (Arthur et al., 1987) and the number of trials (Pantev et al., 1991).

Contrary to some previous findings (Reite et al., 1988) but consistent with others (Mäkelä et al., 1994; Arthur et al., 1987), the present study found the source of P1m to be localized in the intermediate part of the HG. Two bilateral contiguous sources - one radial and the other tangential could generate the surface P1 response, as has been described for N1 (Scherg and Von Cramon, 1985). In light of the orientation and inter-subject anatomical variation of HG, the tangential component may be very difficult to 
record in certain subjects. Liu et al. (1998) explained the weak amplitude of $\mathrm{P} 1 \mathrm{~m}$ as a result of the averaging of potentials with different polarities. In totality, spatially distinct sources for $\mathrm{P} 1 \mathrm{~m}$ and $\mathrm{N} 1 \mathrm{~m}$ were obtained from the MEG data.

In cases where generators were localized using both techniques (such as in the case of the N1 generator), results show a strong spatio-temporal relationship between SEEG recordings and MEG dipoles localized using the SPTF algorithm. N1 generators are easily localizable from MEG recordings (Pantev et al., 1990; Hari, 1990). For the most part, this component has a tangential orientation, which is detected well by MEG captors. Several overlapping sources for components between 70 and $150 \mathrm{~ms}$ are thought to make up the N1 component, such as N1a (75 ms), N1b (102 ms), and N1c (120 ms) (see Näätänen and Picton (1987) for a review). Evaluation of the intracerebral data and magnetic dipole analysis showed the existence of these generators in the auditory cortex. The localization of the N1 generator in the lateral part of the HG is consistent with our previous findings (Liégeois-Chauvel et al., 1994), suggesting that two generators underlie the $\mathrm{N} 1 \mathrm{~b}$ and $\mathrm{N} 1 \mathrm{c}$ components, one in the lateral part of the HG and the other in PT. The N1a component observed from the scalp recordings may be generated from the intermediate part of the HG. The N60/70 component was only observed from the SEEG data. This component has been previously described as the intracerebral equivalent to N1a (Näätänen and Picton, 1987), but its latency is earlier than that of N1a. This component was localized in a medial region of HG, and is easily recorded from intracerebral electrodes. In surface recordings, this component probably corresponds to the beginning of the main N1 component and does not appear as a separate wave. No generator was found intracerebrally in Area 22 for N1. It is difficult, however, to compare source localizations for N1m calculated from the MEG data with the localization of generators obtained intracerebrally, because $\mathrm{N} 1 \mathrm{~m}$ was observed only in Cases 2-4 and the implanted electrodes were positioned at a distance from the generator. Nevertheless, in Case 1, N1a and N1b were observed from SEEG recordings and were localized in the intermediate and lateral parts of the HG, respectively. The localization of N1a dipoles on the patient's MRI confirmed its origin in the intermediate part of the HG.

The generators of components with latencies longer than 110 ms were localized either in Area 22 anterior to the HG (which was probably not observed intracerebrally because of sampling bias) or in PT. Indeed, Reite et al. (1994) suggested the presence of two distinct generators of $\mathrm{N} 1 \mathrm{~m}$ - one in the lateral part of $\mathrm{HG}$ and one immediately anterior to HG. Zouridakis et al. (1990) presented evidence suggesting that the entire duration of the $\mathrm{N} 1 \mathrm{~m}$ component could be accounted for by a dynamic process involving the successive excitation of adjacent cortical sources along the anterior-posterior axis of the auditory cortices. This excitation of cortical sources may also take place along the medial-lateral axis.
P2 generators were localized in PT and/or in Area 22. The localization in PT was found using both techniques, while the localization in Area 22 was found from only the MEG data. We found a different localization of the different sources of N1, which were generated from HG. In Case 3, however, the localization of P2 was different according to the technique used. The high amplitude of P2 observed intracerebrally in PT (i.e. $150 \mathrm{mV}$, which is twice the amplitude found in $\mathrm{HG}$ ) is suggestive of the presence of a generator in this structure (Schwartz, 1998). Based on the MEG data, however, this component appeared to be localized in Area 22. The latter findings are consistent with previous neuromagnetic findings suggesting that the cortical source of the $\mathrm{P} 2 \mathrm{~m}$ response resides approximately from 9 to $10 \mathrm{~mm}$ anterior and $5 \mathrm{~mm}$ medial to that underlying $\mathrm{N} 1 \mathrm{~m}$ (Hari et al., 1987; Joutsiniemi et al., 1989). It seems probable that several sources underlie P2, one in PT that overlaps the N1's source (making its detection difficult) and another in Area 22.

The comparison of SEEG and MEG data was useful in the evaluation of the source localization method currently used in our laboratory and helpful in the creation of solutions to the inverse problem. Given the similarity of localizations obtained using data from both these techniques, one may conclude that the spatio-temporal localization algorithm used in this study is fairly accurate in the detection of sources in HG, PT, and Area 22. Moreover, it was possible to clearly distinguish the sources of P1 and N1 and of N1a and N1b.

To conclude, the study of intracerebral evoked potentials allows for an accurate localization of generators, but only when the latter are localized in regions near the recording leads. The disadvantage of such a method, then, is that an evaluation of all auditory loci (HG, PT, and Area 22) requires intracerebral data from many patients in whom only one auditory structure is generally studied. On the other hand, such a technique is extremely accurate in the localization of the generators of different components, as shown previously (Liégeois-Chauvel et al., 1991, 1994). The localization of generators from the activity recorded from the scalp (i.e. EEG or MEG activity) is less accurate, especially when these generators are in close proximity to one another. The advantage of the latter method is that they give a more global view of the brain activity. The present results illustrate the complementarity of both techniques, with intracerebral recordings allowing for the validation of and a better interpretation of surface recordings.

\section{Acknowledgements}

We would like to thank J.M. Scarabin who was responsible for the implantation of electrodes and surgical intervention, J.M. Badier whose critical comments on a previous version of this paper were of great aid, P. Marquis for his technical assistance, and K. Giraud for revising the English version. 


\section{References}

Arthur DL, Flynn ER, Williamson SJ. Source localization of long latency auditory evoked magnetic fields in human temporal cortex, Current trends in event-related potentials research (EEG suppl 40). Amsterdam: Elsevier, 1987 p. $429-39$.

Bancaud J, Talairach J. Clinical semiology of frontal lobe seizures. In: Chauvel P, Delgado-Escueta AV, Halgren E, Bancaud J, editors. Advances in neurology, vol. 57. New York, NY: Raven Press, 1992. pp. 3-59.

Bancaud J, Talairach J, Bonis A, Schaub C, Szikla G, Morel P, BordasFerrer M. La stéréoélectroencephalographie dans l'Epilepsie: Informations neurophysiopathologiques apportées par l'investigation fonctionnelle stéréotaxique, Paris: Masson, 1965.

Cacace A, Satya-Murti S, Wolpaw J. Human middle latency auditory evoked potentials: vertex and temporal components. Electroenceph clin Neurophysiol 1990;77:6-18.

Deiber MM, Ibanez V, Bastuji H, Fischer C, Mauguière F. Sequential mapping favours the hypothesis of distinct generators for $\mathrm{Na}$ and $\mathrm{Pa}$ middle-latency auditory evoked potentials. Electroenceph clin Neurophysiol 1988;71:187-197.

Farrell DE, Tripp JH, Norgren R, Teyler TJ. A study of the auditory evoked magnetic fields of the human brain. Electroenceph clin Neurophysiol 1980;49:31-37.

Gevins A. Electrophysiological imaging of brain function. In: Toga AW, Mazziota JC, editors. Brain mapping: the methods, New York, NY: Academic Press, 1996. pp. 259-273.

Hari R. The neuromagnetic method in the study of the human auditory cortew. In: Grandori F, Hoke M, Romani GL, editors. Auditory evoked magnetic fields and electric potentials, Basel: Karger, 1990. pp. 222-282.

Hari R, Pelizzone M, Mäkelä JP, Halllstrom J, Linonen L, Lounasmaa OV. Neuromagnetic responses of the human auditory cortex to on and offsets of noise bursts. Audiology 1987;26(1):31-43.

Huotilainen M, Winkler A, Alho K, Escera C, Virtanen J, Ilmoniemi RJ, Jääkeläinen IP, Pekkonen E, Näätänen R. Combined mapping of human auditory EEG and MEG responses. Electroenceph clin Neurophysiol 1998;108:370-379.

Joutsiniemi SL, Hari R, Vilkman V. Cerebral magnetic responses to noise bursts and pauses of different durations. Audiology 1989;28:325-333.

Liégeois-Chauvel C, Musolino A, Chauvel P. Localization of primary auditory area in man. Brain 1991;107:115-131.

Liégeois-Chauvel C, Musolino A, Badier JM, Marquis P, Chauvel P. Evoked potential recorded from the auditory cortex in man: evaluation and topography of the middle latency components. Electroenceph clin Neurophysiol 1994;92:204-214.

Liu LC, Ioannides AA, Müller-Gärtner HW. Bi-hemispheric study of single trial MEG signals of the human auditory cortex. Electroenceph clin Neurophysiol 1998;106:64-78.

Mäkelä JP, Hämäläinen M, Hari R, McEvoy L. Whole-head mapping of middle latency auditory evoked magnetic fields. Electroenceph clin Neurophysiol 1994;92:414-421.

Näätänen R, Picton T. The N1 wave of the electric and magnetic response to sound: a review and an analysis of the component structure. Psychophysiology 1987;24:375-425.

Özdamar Ö, Kraus N. Auditory middle latency responses in humans. Audiology 1983;22:39-49.
Pantev C, Hoke M, Lehnertz K, Lütkenhöner B, Fahrendorf G, Stöber U. Identification of sources of brain neuronal activity with high spatiotemporal resolution through combination of neuromagnetic source localization and magnetic resonance imaging. Electroenceph clin Neurophysiol 1990;75:173-184.

Pantev C, Gallen C, Hampson S, Buchannnan S, Sobel D. Reproducibility and validity of neuromagnetic sources localization using a large array biomagnetometer. Am J EEG Technol 1991;31:83-101.

Pantev C, Elbert T, Makeig S, Hampson S, Eulitz C, Hoke M. Relationship of transient and steady-state auditory evoked fields. Electroenceph clin Neurophysiol 1993;88:389-396.

Pantev C, Bertrand O, Eulitz C, Verkindt C, Hampson S, Schuirer G, Elbert T. Specific tonotopic organizations of different areas of the human auditory cortex revealed by simultaneous magnetic and electric recordings. Electroenceph clin Neurophysiol 1995;94:26-40.

Pelizzone M, Hari R, Mäkelä JP, Huttunen J, Ahlfors S, Hämäläinen M. Cortical origin of middle latency auditory evoked responses in man. Neurosci Lett 1987;82:303-307.

Reite M, Teale P, Zimmerman J, Davis L, Whalen J. Source location of a 50 ms latency auditory evoked field component. Electroenceph clin Neurophysiol 1988;70:490-498.

Reite M, Adams M, Simon J, Teale P, Sheeder J, Richardson D, Grabbe R. Auditory M100 component 1: relationship to Heschl's gyri. Brain Res Cogn Brain Res 1994;2:13-20.

Scherg M, Von Cramon DV. Two bilateral sources of the late AEP as identified by a spatio-temporal model. Electroenceph clin Neurophysiol 1985;62:32-44.

Scherg M, Hari R, Hämäläinen M. Frequency specific sources of the auditory N19-P30-P50 responses detected by a multiple source analysis of evoked magnetic fields and potentials. In: Williamson SJ, et al., editors. Advances in biomagnetism, New York, NY: Plenum Press, 1989. pp. $97-100$

Schwartz D. Localisation des générateurs intra-cérébraux de l'activité MEG et EEG: Evaluation de la précision spatiale et temporelle. Dissertation Université de Rennes 1, 1998.

Schwartz D, Poiseau E, Lemoine D, Barillot C. Registration of MEG/EEG data with MRI: methodology and precision issues. Brain Topogr 1996;9:101-116.

Schwartz DP, Badier JM, Bihoue P, Bouliou A. Evaluation of a new MEGEEG spatio-temporal localization approach using a realistic source model. Brain Topogr 1999;11(4):279-289.

Streletz LJ, Katz L, Hohenberger M, Cracco RQ. Scalp recorder auditory evoked potentials and sonomotor responses: an evaluation of components and recordings techniques. Electroenceph clin Neurophysiol 1977;43:192-206.

Talairach J, Tournoux P. Co-planar stereotaxic atlas of the human brain, Stuttgart: Georg Thieme Verlag, 1988.

Wikswo JP, Gevins A, Williamson SJ. The future of the EEG and MEG. Electroenceph clin Neurophysiol 1993;87:1-9.

Yoshiura T, Ueno S, Iramina K, Masuda K. Human middle latency auditory evoked magnetic fields. Brain Topogr 1996;8:291-296.

Zouridakis G, Simos PG, Papanicolaou AC. Multiple bilaterally asymmetric cortical sources account for the auditory $\mathrm{N} 1 \mathrm{~m}$ component. Brain Topogr 1998;10(3):183-189. 